\begin{tabular}{|c|c|c|}
\hline \multirow{3}{*}{$\begin{array}{r}\text { Case Reports in } \\
\text { Gastroenterology }\end{array}$} & \multicolumn{2}{|c|}{ Case Rep Gastroenterol 2014;8:56-60 } \\
\hline & $\begin{array}{l}\text { DOI: 10.1159/000358555 } \\
\text { Published online: January 30, } 2014\end{array}$ & $\begin{array}{l}\text { (c) } 2014 \text { S. Karger AG, Basel } \\
1662-0631 / 14 / 0081-0056 \$ 39.50 / 0 \\
\text { www.karger.com/crg }\end{array}$ \\
\hline & \multicolumn{2}{|c|}{$\begin{array}{l}\text { This is an Open Access article licensed under the terms of the Creative Common } \\
\text { Attribution-NonCommercial } 3.0 \text { Unported license (CC BY-NC) (www.karger.com/OA } \\
\text { license), applicable to the online version of the article only. Distribution permitted for non } \\
\text { commercial purposes only. }\end{array}$} \\
\hline
\end{tabular}

\title{
Foreign Material in the Gastrointestinal Tract: Cocaine Packets
}

\author{
Nurten Turkel Kucukmetin ${ }^{a} \quad$ Bulent Gucyetmez $^{\mathrm{b}} \quad$ Tuncer Poyraz $^{\mathrm{c}}$ \\ Sadik Yildirim ${ }^{\mathrm{e}}$ Gungor Boztas $^{\mathrm{d}}$ Nurdan Tozun ${ }^{\mathrm{a}}$ \\ ${ }^{a}$ Department of Gastroenterology, Acibadem University, ${ }^{b}$ Intensive Care Unit, 'Department \\ of Radiology and ${ }^{\mathrm{d} D e p a r t m e n t}$ of Gastroenterology, Acibadem International Hospital, and \\ ${ }^{\mathrm{e}}$ Department of General Surgery, Medistate Kavacik Hospital, Istanbul, Turkey
}

\section{Key Words}

Body packers · Cocaine toxicity $\cdot$ Gastrointestinal tract $\cdot$ Treatment $\cdot$ Surgery

\begin{abstract}
Smuggling drugs by swallowing or inserting into a body cavity is not only a serious and growing international crime, but can also lead to lethal medical complications. The most common cause of death in 'body packers', people transporting drugs by ingesting a packet into the gastrointestinal tract, is acute drug toxicity from a ruptured packet. However, more than 30 years after the initial report of body packing, there is still no definitive treatment protocol for the management of this patient group. The treatment strategy is determined according to the particular condition of the patient and the clinical experience of the treatment center. Surgical intervention is also less common now, due to both the use of improved packaging materials among smugglers and a shift towards a more conservative medical approach. Herein, we report a case of toxicity from ingested packets of cocaine that leaked and, despite surgery, resulted in exitus of the patient.

(c) 2014 S. Karger AG, Basel
\end{abstract}

\section{Introduction}

The incidence of smuggling drugs by means of concealing them in body cavities has, over the last 30 years, increased worldwide. The body areas most commonly used for this purpose are the entire gastrointestinal tract, from mouth to anus, the vagina and the ears. Cocaine is one of the most trafficked drugs, followed by heroin. Condoms, latex gloves and balloons are typically used as drug packets for retention in the body [1].

Assist. Prof. Nurten Turkel Kucukmetin, MD

Department of Gastroenterology

Acibadem University

TR-34742 Istanbul (Turkey)

E-Mail nturkel@hotmail.com 
Turkel Kucukmetin et al.: Foreign Material in the Gastrointestinal Tract: Cocaine Packets

\section{Case Report}

A 45-year-old Nigerian patient was admitted to the emergency unit in our hospital, following resuscitation at the airport transit hall due to convulsion, loss of consciousness and cardiopulmonary arrest. Upon physical examination, a mass was palpated in the lower right quadrant of the abdomen. Computed tomography findings showed $5 \times 4 \times 3 \mathrm{~cm}$ lesions and multiple spherical-shaped foreign materials in the stomach and small intestines (fig. 1). Endoscopic examination confirmed retention of 20-25 pieces of $5 \times 4 \mathrm{~cm}$ white, capsuleshaped packets in the stomach of the patient, who was intubated under intensive care conditions (fig. 2). Taking into consideration the overall clinical picture of the patient, the packets were suspected to contain narcotics, and cardiac arrest was thought to have been triggered by rupture of one or more of the packets. The patient was operated on with police present in the room. During the exploration, multiple foreign materials were palpated in the stomach, and starting $120 \mathrm{~cm}$ from the ligament of Treitz, along all the ileum and the right colon. Some of the packets exerted enough pressure to erode the serosa, and some caused almost complete obstruction of the right flexure. A total of 85 condom-wrapped capsules were removed through incisions made at the beginning of the ileum, on the corpus of the stomach and the right transvers colon, and deformation was noted on some of the capsules (fig. 3). The patient died $24 \mathrm{~h}$ after his arrival at the hospital due to cardiac arrest following a peripheral circulatory disorder and hemodynamic instability that suddenly developed at the 8th postoperative hour.

\section{Discussion}

Drug trafficking is a growing international problem. While 'body packers' transport packets of wrapped cocaine within their gastrointestinal tract by swallowing them, 'body pushers' insert the packets into body cavities: the vagina, rectum, or ear [2]. 'Body packer syndrome' was first described in 1981 for persons who died from toxicity following the ingestion of drug packets they were transporting [3]. Latex gloves, condoms and toy balloons are typically used as drug packets for retention in the body. Under normal conditions, spontaneous passage of a drug-filled packet through the digestive system occurs within $30 \mathrm{~h}$ [1]. However, in order to delay the bowel transit time, body packers may deliberately take anticholinergic agents to reduce bowel motility. Once they are at the point of arrival, they use laxatives, cathartics or enemas to facilitate passage of the packets [1, 3, 4]. Each swallowed packet contains 3-6 g of cocaine on average $[1,5]$. The first case of non-fatal intoxication due to cocaine-filled balloons was reported in 1975 in Florida [3, 6, 7].

Persons who transport drugs by internal bodily concealment are caught either because of their suspicious behavior, intestinal obstruction caused by packets or intoxication from rupture of and leakage from one or more packets. Most body packers are asymptomatic. Typical suspicious characteristics of body packers include unusual behaviors, specific routes of travelling, sitting motionless, refusal to eat or drink during the journey, and the particular smell of breath caused by the stomach acid covering the packets $[2,3,8]$. Physical examination of asymptomatic body packers is usually unremarkable. Rectal and vaginal examinations should also be a regular part of these examinations.

Due to high rates of false-negative results caused by cocaine metabolites, urine drug screening is not of diagnostic value for asymptomatic body packers. Plain abdominal radiography is the most common examination method. A review of previous studies shows that although plain abdominal radiography has a diagnostic specificity of $97 \%$, its sensitivity 
Turkel Kucukmetin et al.: Foreign Material in the Gastrointestinal Tract: Cocaine Packets

for excluding body packing is low for cases where the packets cannot be detected [7, 8]. If abdominal radiography shows unclear results, abdominal tomography (CAT) or contrast passage radiography is performed. Compared to contrast passage radiography, CAT is an easier and more reliable method which can also measure density and reveal information about the localization and number of packets $[8,9]$.

The risk of complication increases in direct relation to the length of waiting time of body packers. Other factors, such as the type and amount of illicit drug, the duration of packet retention and the method and localization of concealment, also increase complication risks $[1,10]$. Drug toxicity varies according to the type and absorption rate of the drug. Clinical signs may include a wide range of symptoms from general convulsion to tachycardia, from deep shock to metabolic disorders. The lack of an antidote makes cocaine intoxication particularly dangerous. Cocaine intoxication may present through symptoms of anxiety, diaphoresis, tachycardia, hypertension, hyperthermia, dilated pupils, hallucination, convulsion and cardiovascular collapse (myocardial ischemia and infarction) $[2,4,8,11]$. Pregnant women are more prone to cocaine toxicity due to low levels of cocaine-degrading plasma esterase enzyme during gestation, and high levels of progesterone further slows the metabolism of cocaine [12].

Symptomatic cases present with obstruction symptoms such as abdominal pain, nausea, vomiting and an inability to pass gas or stool [1, 8]. In a study of 70 body packers by de Beer et al. [5], 5.1\% had intestinal obstruction, 4.2\% hemorrhagic complications and $2.3 \%$ convulsions. When swallowing packets large in size and number, anomaly in the gastrointestinal tract and another concomitant diseases increase the risk of obstruction. Perforation depends on obstruction of local ischemia.

Patients receive symptomatic treatment based on the clinical findings. The treatment aims to ensure the removal of the cocaine packets from the gastrointestinal tract at the earliest stage. Asymptomatic patients are treated conservatively with laxatives and promotility agents until all packets are passed [4]. There is no consensus on conservative treatment. While some authors suggest the use of paraffin oil as a reliable laxative, others argue that it should be avoided because paraffin can cause deterioration of packets. The current treatment of choice is polyethylene glycol (PEG), which does not disturb electrolyte and liquid balance and does not lead to packet rupture and toxicity [7, 8].

Surgery is indicated in case of gastrointestinal obstruction, perforation, cocaine toxicity or retention of drug packets beyond 5 days despite conservative treatment $[5,6,10]$. There is no consensus on the timing of surgery in asymptomatic patients who cannot spontaneously pass drug packets. While some authors consider 5 days as sufficient time to allow spontaneous passage of drug packets, other suggest times varying from $27 \mathrm{~h}$ to 7 days [8]. Surgical treatment aims to perform a complete exploration of the abdomen, to clean the gastrointestinal tract and to clear the symptoms of obstruction. Mortality is low for surgeries performed due to obstruction. Palpating the intestines during the surgery does not conclusively confirm that all packets are removed. Therefore, a postoperative plain abdominal radiography should also be performed. One of the most important postoperative complications is wound infection, the risk of which increases in case of multiple enterotomies and colostomy [5].

In conclusion, drug smuggling by internal bodily concealment was first reported in the 1970s. However, more than 30 years after the initial report of body packing, no definitive treatment protocol has been suggested in the literature. The treatment strategy is determined according to the particular conditions of the patient and the clinical experience of the treatment centers. 


\begin{tabular}{l|l}
\hline \multicolumn{2}{l}{ Case Rep Gastroenterol 2014;8:56-60 } \\
\hline DOI: 10.1159/000358555 & $\begin{array}{l}\text { C 2014 S. Karger AG, Basel } \\
\text { www.karger.com/crg }\end{array}$ \\
\hline
\end{tabular}

Turkel Kucukmetin et al.: Foreign Material in the Gastrointestinal Tract: Cocaine Packets

\section{Disclosure Statement}

The authors declare they have no conflicts of interests to disclose.

\section{References}

1 Alkan N: Body packer syndrome (in Turkish). Bagimlilik Dergisi 2004;5:84-90.

-2 Schaper A, Hofmann R, Bargain P, Desel H, Ebbecke M, Langer C: Surgical treatment in cocaine body packers and body pushers. Int J Colorectal Dis 2007;22:1531-1535.

-3 Koehler SA, Ladham S, Rozin L, Shakir A, Omalu B, Dominick J, Wecht CH: The risk of body packing: a case of a fatal cocaine overdose. Forensic Sci Int 2005;151:81-84.

4 Khan FY: The cocaine 'body-packer' syndrome: diagnosis and treatment. Indian J Med Sci 2005;59:457-458.

5 de Beer SA, Spiessens G, Mol W, Fa-Si-Oen PR: Surgery for body packing in the Caribbean: a retrospective study of 70 patients. World J Surg 2008;32:281-285; discussion 286-287.

6 Silverberg D, Menes T, Kim U: Surgery for 'body packers' - a 15-year experience. World J Surg 2006;30:541546.

7 Beckley I, Ansari NA, Khwaja HA, Mohsen Y: Clinical management of cocaine body packers: the Hillingdon experience. Can J Surg 2009;52:417-421.

-8 Yegane RA, Bashashati M, Hajinasrollah E, Heidari K, Salehi NA, Ahmadi M: Surgical approach to body packing. Dis Colon Rectum 2009;52:97-103.

\9 Taheri MS, Hassanian-Moghaddam H, Birang S, Hemadi H, Shahnazi M, Jalali AH, Shakiba M, Nahvi V: Swallowed opium packets: CT diagnosis. Abdom Imaging 2008;33:262-266.

10 Kulkarni VM, Gandhi JA, Gupta RA, Deokar RB, Karnik ND, Nadkar MY: Body packer syndrome. J Postgrad Med 2012;58:225-226.

11 Karch SB: Cocaine cardiovascular toxicity. South Med J 2005;98:794-799.

12 Cordero DR, Medina C, Helfgott A: Cocaine body packing in pregnancy. Ann Emerg Med 2006;48:323-325.

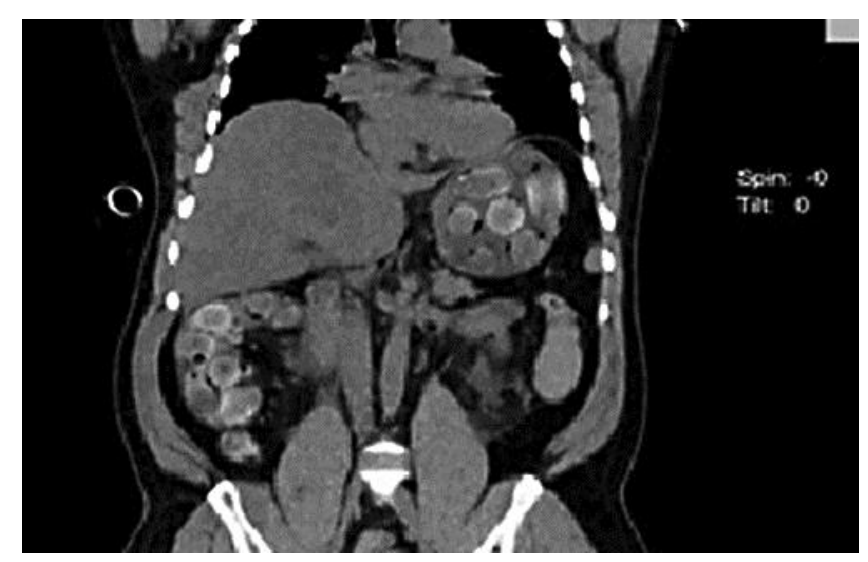

Fig. 1. Computed tomography of the abdomen showing foreign materials in the stomach and small intestines. 
Turkel Kucukmetin et al.: Foreign Material in the Gastrointestinal Tract: Cocaine Packets

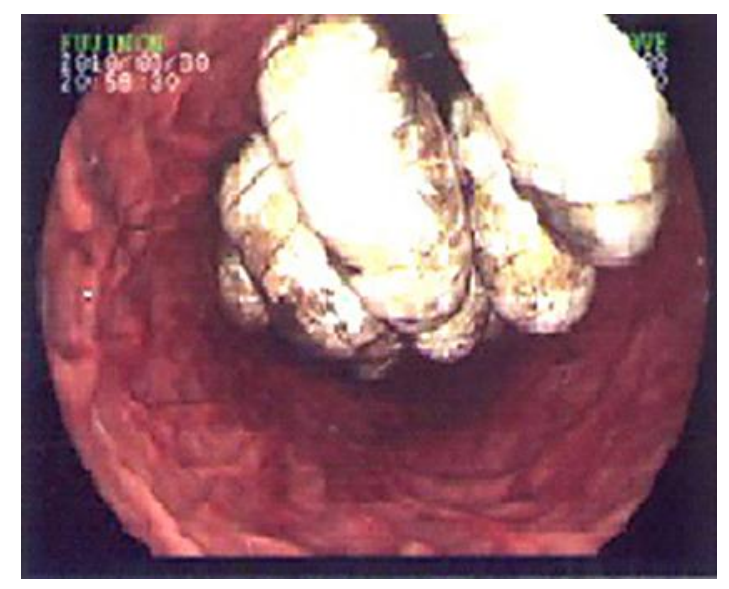

Fig. 2. Endoscopic imaging of the cocaine capsules.

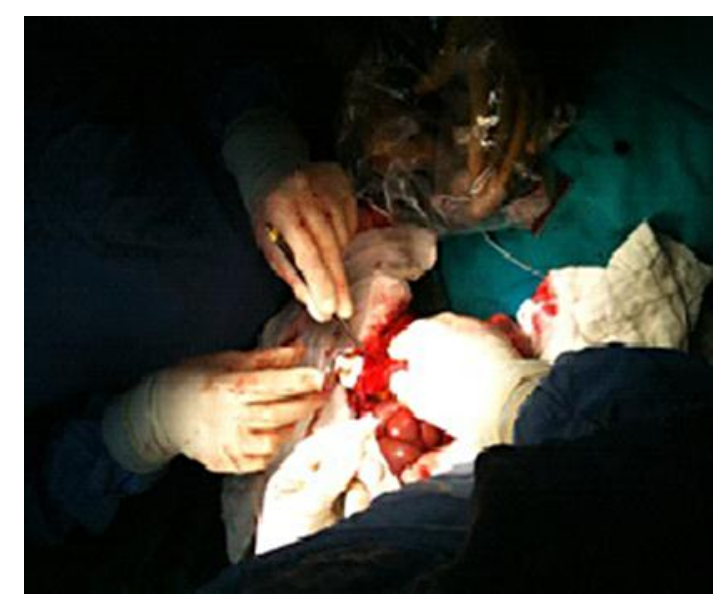

Fig. 3. Surgical extraction of the capsules. 